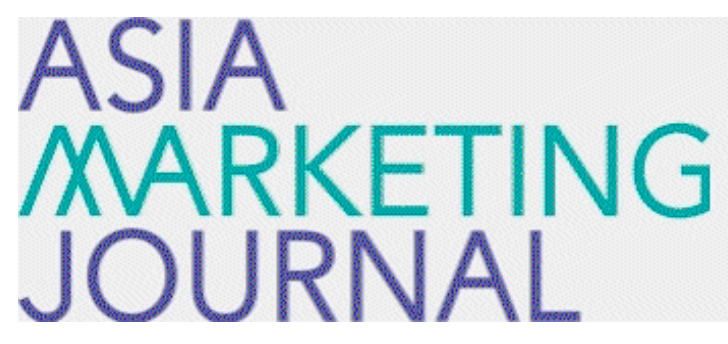

ASIA MARKETING JOURNAL

Volume 18 | Issue 4

Article 4

$1-31-2017$

\title{
Impacts of Reward Accrual Effort on Redemption Behavior in a Multi-Vendor Loyalty Program
}

Ji Yoon Kim

Janghyuk Lee

Sang Yong Kim

Follow this and additional works at: https://amj.kma.re.kr/journal

Part of the Marketing Commons

\section{Recommended Citation}

Kim, Ji Yoon; Lee, Janghyuk; and Kim, Sang Yong (2017) "Impacts of Reward Accrual Effort on Redemption Behavior in a Multi-Vendor Loyalty Program," Asia Marketing Journal: Vol. 18 : Iss. 4 , Article 4.

Available at: https://doi.org/10.15830/amj.2017.18.4.77

This Article is brought to you for free and open access by Asia Marketing Journal. It has been accepted for inclusion in Asia Marketing Journal by an authorized editor of Asia Marketing Journal. 


\title{
Impacts of Reward Accrual Effort on Redemption Behavior in a Multi-Vendor Loyalty Program*
}

\author{
Ji Yoon Kim** \\ Janghyuk Lee*** \\ Sang Yong Kim****
}

This research explores two key facets of behavior (reward point accrual and redemption) that consist of a loyalty program. It focuses on assessing the impact of accrual effort level on three types of redemption behavior: speed, unit size, and hedonic preference at the individual level by using large scale transaction data from a multi-vendor loyalty program providing flexible environment for point accrual and redemption. Findings from this research demonstrate that customers tend 1) to speed up point redemption, 2) to enlarge the size of redeemed points, and 3) to prefer utilitarian rewards as the level of effort at the accrual stage of reward point increases.

Key words: Effort level, Redemption behavior, Multi-vendor loyalty program

The Loyalty program is a very effective marketing tool for companies hoping to build and to nurture long-lasting relationships with customers. Most manufacturing companies in the business to consumer industry face systematic difficulties in identifying their customers unless they sell directly to them, like Dell, or unless their customers register durable products after purchase. Customer identification is the first step to customer relationship management as it allows companies to improve their marketing performance by distinguishing between new customer acquisition and existing customer retention related activities(Reinartz et al. 2005; Thomas 2001). Many service companies can benefit from a successful loyalty program if it leads its customers to consolidate their spending into a single company at a given category.

\footnotetext{
* The authors thank SK Planet for providing the data and this work was supported by the Ministry of Education of the Republic of Korea and the National Research Foundation of Korea (NRF-2015S1A5B6036421).

** Assistant professor, Chonnam National University, Dept of Business Administration (jykim2016@jnu.ac.kr)

*** Associate professor, Korea University, Business School (janglee@korea.ac.kr), Corresponding author

**** Professor, Korea University, Business School (sangkim@korea.ac.kr)
} 
While pioneers like General Motors (GM card) and American Airlines (AAdvantage) started out with single brand or single company loyalty programs, loyalty programs providing a wide range of stores for reward accrual and redemption such as Air Miles in Canada, Payback in Germany, $\mathrm{T}$ point in Japan, and Nectar in England have emerged in recent years. These loyalty programs select one or multiple affiliate partner companies in a given category and encourage their customers to purchase at affiliate partner companies by increasing reward values through cross redemption opportunities. Such loyalty programs are called as multi-vendor loyalty programs and a specific subset where a specialized operator manages coalition partners are called coalition programs (Blattberg et al. 2008; Dorotic et al. 2011). The defining trait of these aggregate loyalty programs is that they allow consumers to collect and use points through diverse means which, unlike single brand programs, can span across diverse brands and companies. In other words, the fact that competing brands coexist within these programs means that it is easier to observe general trends of consumer behavior in comparison to single brand based loyalty programs.

In general, a loyalty program encompasses two key customer behaviors: reward accrual and reward redemption. Customers of a loyalty program can accrue reward points according to transaction type, value, and accrual rate. They also receive rewards by redeeming reward points for available offers and/or cash. Customers of a loyalty program differ in terms of their level of effort for point accrual during the point accrual and redemption process, as well as their chosen redemption reward size and type (Kivetz and Simonson 2002; Kivetz 2003; Kivetz 2005). Hsee et al. (2003) showed experimentally that consumers take an unbalanced view between effort - medium (e.g., reward points) and medium - outcome attainment due to diverse medium effects such as the illusion of advantage, certainty, and linearity. To explain the dynamics between point accrual and redemption behavior Nunes and Drèze (2006) showed the progressive endowment effect, which demonstrates that the frequency of point accrual behavior accelerates as one approaches a goal through car wash and restaurant experiments. These findings were extended into a study

〈Figure 1〉 Conceptual framework of the reward impacts of effort level on redemption behavior

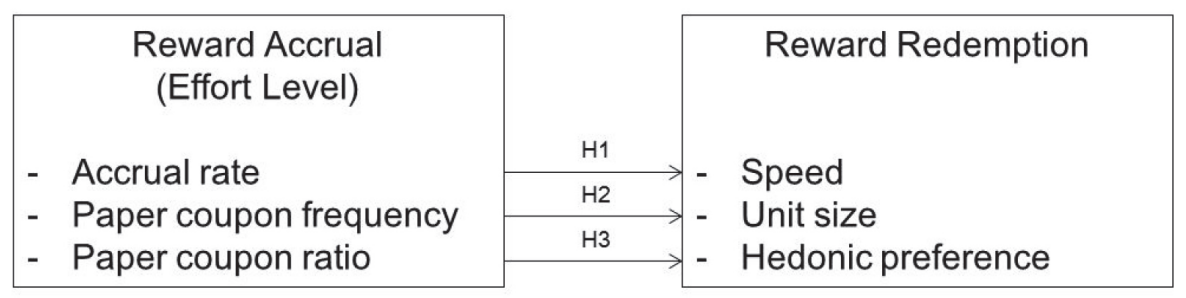


showing that the learning effect affected accrual behavior after the goal (status upgrade) was achieved, based on empirical data from an airline company (Drèze and Nunes 2011).

To advance the findings of previous research on accrual and redemption dynamics, we analyzed the effort level for point accrual and assessed its impact on three different angles of redemption behavior: speed, unit size and hedonic preference. As most loyalty programs own large scale transaction data, including reward accrual and redemption, we developed proxy variables to represent the effort level for point accrual by calculating the average accrual rate from aggregated accrual transaction data and assessing paper coupon related transaction data. Redemption speed was calculated by calculating the duration of point possession between its accrual and redemption based on the first in first out method. The rest of this study includes 1) theoretical background and hypothesis development, 2) methodology (data, measures, and analysis method), 3) results, 4) discussion (empirical findings, managerial implications, limitations and future research).

\section{Theoretical Background and Research Hypothesis}

Loyalty program-related consumer behavior can be largely divided into point accrual and point redemption. We focused on the level of effort exerted to accrue points and point redemption behavior such as speed, unit size, and hedonic preference.

\subsection{Point Accrual Behavior: Effort Level}

The effort level can be defined as the level of compliance by the consumers to the requirements of the loyalty program (Kivetz and Simonson 2002; Kivetz 2003; Kivetz 2005). The types of effort manipulated in previous research experiments were often related to either purchase frequency or the amount of points required to receive the proposed reward. In Kivetz and Simonson (2002), the conditions chosen for effort level were the number of car rentals, hotel stays, purchase amount and e-points. Activities such as purchase frequency at gas station and purchase amount at department store were mobilized to differentiate the level of effort (Kivetz and Simonson 2003). In addition, activities not directly related to purchase were sometimes considered as effort. Hsee et al. (2003) included tasks such as whether to buy the CD at the five-minute-away branch or the sixminute-away branch, complete a 20-minute survey or a 25-minute survey. Cardozo (1965) manipulated shopping tasks of 15 minutes and 1 hour to write down one feature which impressed subjects. Consumers tended to perceive the level of effort exerted relatively, a phenomenon named idiosyncratic fit (Kivetz and Simonson 2003). 
When consumers felt advantaged in comparison to others by the requirements of the loyalty program, they would prefer high effort loyalty programs to low effort programs.

\subsection{Point Redemption Behavior}

Research into redemption behavior within loyalty programs can be considered important for the following reasons. Firstly, studies show that the rewards gained by the consumer through loyalty programs increases their loyalty to related businesses (Gomez, Arranz and Cillan 2006; Meyer-Waarden 2007). Secondly, redemption frequency can mark the difference between success and failure for a loyalty program. The customer's redemption habit is a gain for the company as the knowledge gained from understanding them can be applied elsewhere, while satisfied customers will spend more and increase profit (Humby, Hunt and Phillips 2003; Taylor and Neslin 2005). Thirdly, 'redemption' is a major perk for loyalty program members as well as an important incentive from the customer's point of view. According to Nunes and Drèze (2006), in order for a loyalty program to be attractive, it must increase consumption behavior, while Meyer-Waarden and Benavent (2006) state that when running a loyalty program, the personalization of the reward and communication process is of more importance to members than the particulars of the program itself. To cope with its importance, we measure three different angles of redemption behavior: speed, unit size and hedonic preference.

\subsubsection{Speed}

Discounted utility theory (Lowenstein and Prelec 1992) considers that delays are negative not only because they cause stress to consumers thus decreasing overall satisfaction but also because they decrease the utility of the product over time. In other words, people prefer the now to the future when achieving gains, in accordance with the temporal discounting theory. Mischel, Grusec and Master (1969) showed that the value of a product decreases with time while Delleart and Kahn (1999) found that the stress and worry inflicted on consumers by delays could lead to negative feelings towards the service provider. However, in some cases consumers would prefer delaying to achieve gains. According to Nisan (1973), people learn through socialization that some rewards, such as birthday presents, are worth waiting for. Moreover, Caplin and Leahy (2001) found that the act of anticipation itself can in fact make the reward more valuable. For example, it was found that in some events such as the promise of a kiss from a favorite actor, the participants would favor savoring the wait through self-imposed delays (Loewenstein 1987). Furthermore, Loewenstein and Prelec (1993) showed that subjects would prefer ascending reward tiers over descending tiers for the same reason. If consumers consider 
the delay of point redemption negative (positive), they accelerate (slow down) point redemption behavior.

\subsubsection{Unit size}

According to Thaler's hedonic editing hypothesis (1980), gain should be divided and losses aggregated to increase perceived value. Multiple gains of small size are more satisfying than a single gain of the same sum. In loyalty program context, customers could be better off by redeeming reward points in a small unit size in order to maximize their perceived value. Also, each redemption activity should require a kind of transaction cost (e.g., presenting a loyalty card for swiping at card terminal). The optimum unit size of each customer would depend on two factors, the degree of value function slope and transaction cost.

\subsubsection{Hedonic preference}

Previous studies categorized technology or performance inclined products as utilitarian and aesthetic or self-expression inclined products as hedonic (Mittal 1989; Vaughn 1980; Zaichkowsky 1985). The reason for these categorizations is because when consumers evaluate products, they tend to see some as either intrinsically utilitarian or intrinsically hedonic, even when both facets are present (Batra and Ahtola 1991). Hedonic products are attractive, luxurious, and tend to place emphasis on pleasure or excitement and result from affective decisions, whereas utilitarian products are practical, fulfill the $\mathrm{ba}^{-}$ sic needs of a consumer or aid them in their work (Hirschman and Holbrook 1982). Therefore, we can distinguish between the two by saying that hedonic products offer anticipation of a future pleasure while utilitarian products alleviate current discomforts (Berry 1994). The rewards offered by loyalty program were divided into necessities and luxuries (Kivetz and Simonson 2002). Items such as fuel and oil change with a practical function can be classified as necessities while items with an emotional function such as Burgundy wine and gourmet treats were classified as luxuries.

\subsection{Hypothesis Development}

\subsubsection{Effort level and redemption speed}

A customer may determine the optimal speed of redemption based on his/her temporal discount rate and the perceived value of reward. We try to investigate whether a consumer having put more effort to accrue points tends to accelerate his/her speed of reward redemption as his/her temporal discount rate gets larger. Thaler (1980) reported that future behavior could be influenced by cost spent in the past, known as sunk cost effect. So we suppose the accrual effort as a sunk cost that could influence the rate of temporal discount of loyalty program members. 
H1: The higher the effort level of point accrual by customers, the faster their speed of point redemption.

\subsubsection{Effort level and redemption point unit size}

Kahneman and Tversky (1979) explained that since the reference point is indicative of the perceived status quo, therefore if the expectation or aspiration level differs from the status quo, the relative placement of gains and losses can differ. Therefore, in this study the status quo differs from the neutral point as consumers' expectations change with their effort level. If the perceived value of the reward is lower than expectations due to effort, it will be perceived as loss. Therefore, the effort level of a consumer affects their expectations of the reward which moves the reference point from 0 to the right. If the consumer is motivated by the prospect of reward to raise their effort level, they will expect bigger rewards (Kivetz 2003). As the required level of effort is higher, the reference point of the value function shifts to the right. Therefore, the same level of reward will be perceived as less valuable (Kivetz 2003) which leads to a tendency for costumers to consume in large sums. Based on the possible shift of value function due to effort, we formulate this second hypothesis.

H2: The higher the effort level of customers, the larger their unit size of redeemed points.

\subsubsection{Effort level and redemption hedonic preference}

Previous research suggested that the consumption of hedonic goods or services induces a sense of guilt, regardless of actual cost (Lascu 1991; Prelec and Herrnstein 1991; Strahilevitz and Myers 1998; Thaler 1980). For example, if a vacation resort or restaurant were to offer free meals, consumers could find it burdensome due to guilt. This feeling of guilt can be alleviated through altruistic actions or effort such as giving to charity or working hard (Kivetz 1999). Kivetz and Simonson (2002) showed that high-effort subjects would favor hedonic rewards, a fact which was attributed to guilt alleviation. Therefore, the expected outcome is that the effort level of the consumer will relieve guilt and lead to higher rates of point consumption for hedonic purposes. Therefore, we draw our third hypothesis.

H3: The higher the effort level of customers, the higher their rate of point redemption for hedonic products.

\section{Methodology}

\subsection{Data}

Our study uses primary data from OK CashBag, 
a multi-vendor loyalty program operated by SK Marketing \& Company, currently SK Planet. As of 2008, OK CashBag had 50 off-line affiliate partners having 45,000 stores such as TGI Fridays (restaurant), FamilyMart (convenience store), Shinsegae (department store), SK energy (gas station), and Etude House (cosmetic retailer) as well as 100 on-line affiliate partners. OK CashBag provided 300 paper coupon types of 60 major consumer package companies whose coupons were handled at 5,000 retail stores. To assure the ease of use of its membership card, OK CashBag was affiliated to 20 financial institutions with 50 associated credit cards. OK CashBag program encourages its customers to accrue reward points by presenting a card when they purchase from various affiliate partners. OK CashBag customers can mainly accrue reward points through four methods: (1) by presenting their OK CashBag membership card when purchasing at a store of affiliate partners, (2) by using a credit card associated with OK
CashBag, (3) by linking recurring bill payment (e.g., mobile telecom, utilities) with OK CashBag, (4) by collecting paper coupons. In the case of paper coupons, OK CashBag customers must buy products with OK CashBag coupons attached on the packaging, then manually cut out and glue them on a collection board and take them to an OK CashBag store or collection center in order to convert them into redeemable points. This study is based on transaction data from 2007 to 2008 of 33,805 customers who had joined OK CashBag program between 1999 and 2006.

\subsection{Measures}

\subsubsection{Accrual behavior: effort level}

The effort level is defined as the level of compliance by customers to the requirements of the loyalty program (Kivetz and Simonson 2002; Kivetz 2003; Kivetz 2005). This compliance can be measured in several ways such

〈Table 1〉 Customer Characteristics

\begin{tabular}{lcrrrr}
\hline \multicolumn{1}{c}{ Variables } & Obs & Mean & Min & Max & Median \\
\hline Gender & 33805 Male (38.3\%) & & & & \\
Marital Status & 33720 Married (23.9\%) & & & & \\
Online & 33805 Online (89.7\%) & & & & \\
Tenure (year) & 33805 & 8 & 2 & 13 & 9 \\
Age & 33805 & 32 & 14 & 57 & 30 \\
The Number of Cards Held & 33805 & 8 & 1 & 92 & 7 \\
Purchase Amount (US\$)* & 30960 & 415 & 0 & 75365 & 269 \\
& 2007 & 489 & 0 & 47009 & 300 \\
\hline
\end{tabular}

* 1 US $\$=1000$ Korean Won 
as the number of rentals (in the case of car rental service), total sum spent (in case of retailer), or the number of nights stayed (in case of hotel) (Kivetz and Simonson 2002). We quantified effort level from three different angles in order to render its multiple dimensions. For the first variable, we measured the average rate of point accrual, named 'Effort: Accrual rate', as affiliate partners of OK CashBag offer different rate of point accrual 1\% 3\% per amount spent. We assumed that customers with high point accrual rate would have put in more effort (information search, store visit, etc.) to select affiliate partners providing high accrual rate than customers with low point accrual rate. Consequently, average point accrual rate would represent the effort level of loyalty program customers (Anderson et al. 1979). For the second and third variables, we focused on the difference of effort level across ways of point accrual. Among the four major methods of accruing reward points, collecting paper coupons was considered the most effort demanding method. The average of point accrual by paper coupon is 4.91 on a 5 point Likert scale. Other three methods have 3.37, 3.55, and 3.61 on average. To measure the absolute effort level related to point accrual, we counted the frequency of paper coupon accrual, named 'Effort: Coupon frequency' similar to effort level variables such as the number of car rentals and hotel stays measured by Kivetz and Simonson (2002). To assess the effort level relatively, we measure the proportion of point accrual frequency of paper coupon out of the total point accrual frequency, named 'Effort: Coupon proportion'.

\subsubsection{Redemption behavior: speed, unit size, hedonic preference}

The point redemption speed of customers is calculated by assessing their transaction data of point accrual and redemption. We applied the 'First In First Out' (FIFO) method (Ogden and Ogden 2005) and counted the elapsed time (in terms of day) between when a point was accrued and when it was redeemed. The FIFO method supposes that the oldest entry will be processed first. Whenever points were redeemed, they were supposed to have been from the oldest available instance of point accrual. Therefore, the longer each point 'stayed' in possession of customers, the slower their redemption speed can be seen as being. (Appendix for calculation in detail). The size of redeemed points was measured simply by assessing the number of redeemed points. To measure the degree of hedonic and utilitarian of affiliate partners, we conduct a survey involving 400 randomly chosen OK CashBag customers to assess the hedonic orientation of affiliate partners. They answered for a question with a seven point bi-polar scale between utilitarian and hedonic affiliate partners. The average of answers is taken and transformed into a numeric scale between 0 for perfect utilitarian outlet and 1 for perfect hedonic 
$\langle$ Table 2〉 Descriptive statistics

\begin{tabular}{lrrrrrrr}
\hline \multicolumn{1}{c}{ Variables } & Year & Obs \# & \multicolumn{1}{c}{ Mean } & \multicolumn{1}{c}{ Min } & \multicolumn{1}{c}{ Max } & Median & \multicolumn{1}{l}{ S.D. } \\
\hline Effort: Accrual Rate & 2007 & 30423 & 0.03 & 0.00 & 0.95 & 0.02 & 0.04 \\
& 2008 & 30938 & 0.02 & 0.01 & 0.97 & 0.02 & 0.04 \\
Effort: Coupon Frequency & 2007 & 30960 & 1.55 & 0.00 & 462.00 & 0.00 & 6.50 \\
& 2008 & 31173 & 2.36 & 0.00 & 1463.00 & 0.00 & 13.26 \\
Effort: Coupon Ratio & 2007 & 30960 & 0.03 & 0.00 & 1.00 & 0.00 & 0.08 \\
& 2008 & 31173 & 0.03 & 0.00 & 1.00 & 0.00 & 0.10 \\
Redemption Speed & 2007 & 18724 & 112.79 & 0.00 & 364.00 & 95.67 & 70.42 \\
& 2008 & 19079 & 113.05 & 0.00 & 364.75 & 96.62 & 70.84 \\
Redemption Unit Size & 2007 & 18724 & 6059.00 & 10.00 & 204500.00 & 3180.00 & 9173.00 \\
& 2008 & 19079 & 6719.83 & 1.00 & 1000000.00 & 12850.00 & 12849.00 \\
Redemption Hedonic Preference & 2007 & 18724 & 0.84 & 0.00 & 1.00 & 1.00 & 0.27 \\
& 2008 & 19079 & 0.78 & 0.00 & 1.00 & 1.00 & 0.32 \\
\hline
\end{tabular}

one. 496 affiliate partners were assessed with the average of 0.46 . Our measure of hedonic preference differs from that in previous research. In previous research, the distinction between hedonic and utilitarian is measured at product level. But in our research we apply it to business level with the assumption that affiliate partners running hedonic business tend to provide hedonic products as a reward.

The three variables representing key aspects of redemption behavior in Table 3 show relatively low correlation (0.21 for speed and unit size, -0.30 for speed and hedonic preference and -0.12 for unit size and hedonic preference). It means that three types of redemption behavior on which we focused are quite independent one to each other and it helps us understand the multiple facets of redemption behavior in a single study.

\subsection{Analysis Method}

We used a multiple regression analysis to assess the impact of three effort level variables (accrual rate, coupon frequency and ratio) on three types of redemption behavior: speed, unit size, hedonic preference after controlling variables such as gender, marital status, being online, tenure, age, the number of cards held, and purchase amount. Consumer demographics such as age (Jones et al. 2000; Ngobo and DevalletEzanno, 2010; Patterson 2007) and gender (Jones et al. 2000; Patterson 2007) have been found to have an impact on both the consumer relationship with the service organization and the loyalty and satisfaction of consumers toward service products (Daughtrey, Vowles, and Black 2013; Patterson 2007). We control the duration of relationship as customer's tenure infers often 
$\langle$ Table 3〉 Correlation matrix

\begin{tabular}{|c|c|c|c|c|c|c|c|c|c|c|c|c|c|c|}
\hline & & 1 & 2 & 3 & 4 & 5 & 6 & 7 & 8 & 9 & 10 & 11 & 12 & 13 \\
\hline 1 & Redemption Speed & 1.00 & & & & & & & & & & & & \\
\hline 2 & Redemption Unit Size & 0.21 & 1.00 & & & & & & & & & & & \\
\hline 3 & Redemption Hedonic Preference & -0.12 & -0.30 & 1.00 & & & & & & & & & & \\
\hline 4 & Effort: Accrual Rate & -0.02 & 0.08 & -0.05 & 1.00 & & & & & & & & & \\
\hline 5 & Effort: Coupon Frequency & -0.04 & 0.09 & -0.05 & 0.25 & 1.00 & & & & & & & & \\
\hline 6 & Effort: Coupon Ratio & -0.04 & 0.07 & -0.04 & 0.36 & 0.61 & 1.00 & & & & & & & \\
\hline 7 & Gender & 0.06 & 0.10 & -0.06 & -0.01 & -0.07 & -0.10 & 1.00 & & & & & & \\
\hline 8 & Marital Status & 0.03 & 0.17 & -0.11 & 0.03 & 0.09 & 0.08 & 0.09 & 1.00 & & & & & \\
\hline 9 & Online & -0.04 & -0.08 & 0.04 & 0.04 & 0.06 & 0.06 & 0.02 & -0.01 & 1.00 & & & & \\
\hline 10 & Tenure & 0.02 & 0.14 & -0.08 & -0.03 & 0.05 & 0.01 & 0.13 & 0.21 & 0.14 & 1.00 & & & \\
\hline 11 & Age & 0.08 & 0.30 & -0.22 & 0.01 & 0.02 & 0.03 & 0.17 & 0.30 & -0.10 & 0.29 & 1.00 & & \\
\hline 12 & The Number of Cards Held & -0.01 & 0.17 & -0.07 & 0.03 & 0.04 & 0.11 & 0.06 & 0.22 & 0.21 & 0.40 & 0.12 & 1.00 & \\
\hline 13 & Purchase Amount & -0.06 & 0.21 & -0.06 & -0.02 & 0.16 & 0.04 & 0.03 & 0.11 & 0.06 & 0.13 & 0.09 & 0.27 & 1.00 \\
\hline
\end{tabular}

*All correlations in bold are significantat $p<.05$.

the level of loyalty (Bell et al. 2005; Bolton 1998). Purchase amount was added as a control variable in order to show the amount impact on point redemption behavior separately.

\section{Results}

The magnitude of influence of the three effort proxy variables related to point accrual behavior on point redemption behavior, in terms of speed, unit size, and hedonic preference is presented in Table 4, 5, and 6. The results from 2007 and 2008 are highly consistent except for the influence of 'Effort: Accrual rate' on 'Hedonic preference'.

All three effort proxy variables turned out to reduce the duration of point redemption in Table 4. As customers put in more effort to accrue reward points, they tended to accelerate their redemption instead of slowing down. This redemption speed acceleration led to a shortened duration of point redemption. For example, if a customer's effort level in terms of average accrual rate ('Effort: Accrual rate') increased by $10 \%$, s/he tended to shorten the average duration of point redemption almost by 4 days. Based on the sunk cost effect (Thaler 1980) and the payment depreciation phenomenon (Gourville and Soman 1998) we developed hypothesis 1, expecting an 'acceleration effect' of the point accrual effort. This finding confirms our hypothesis 1 by showing that acceleration point redemption is influenced by point accrual effort level across the three proxy effort level variables. 
$\langle$ Table 4〉 Impacts on redemption speed

\begin{tabular}{|c|c|c|c|c|c|c|c|c|c|}
\hline \multicolumn{10}{|l|}{2007} \\
\hline Variable & Beta & $\mathrm{t}$-value & Beta & $\mathrm{t}$-value & Beta & t-value & Beta & $\mathrm{t}$-value & VIF \\
\hline Intercept & 95.731 & $22.17^{* * * *}$ & 95.762 & $22.20^{* * * *}$ & 96.131 & $22.22^{* * * *}$ & 95.004 & $22.02^{* * * *}$ & \\
\hline Gender & 7.091 & $6.35^{* * * *}$ & 6.622 & $5.90^{* * * *}$ & 6.420 & $5.70 * * *$ & 6.311 & $5.61^{* * * *}$ & 1.09 \\
\hline Marital Status & 0.897 & 0.69 & 1.486 & 1.14 & 1.593 & 1.22 & 1.343 & 1.03 & 1.22 \\
\hline Online & -9.215 & $-3.64^{* * *}$ & -9.465 & $-3.73^{* * *}$ & -9.268 & $-3.65^{* * * *}$ & -8.044 & $-3.18^{* * * *}$ & 1.06 \\
\hline Tenure & -0.031 & -0.09 & 0.048 & 0.14 & 0.035 & 0.11 & -0.025 & -0.07 & 1.26 \\
\hline Age & 0.901 & $9.02^{* * * *}$ & 0.876 & $8.78^{* * * *}$ & 0.884 & $8.86^{* * *}$ & 0.899 & $9.02^{* * *}$ & 1.40 \\
\hline The Number of Cards Held & -0.125 & -1.11 & -0.128 & -1.14 & -0.146 & -1.30 & -0.121 & -1.07 & 1.23 \\
\hline Purchase Amount $(10,000)$ & -0.054 & $-9.17^{* * *}$ & -0.051 & $-8.66^{* * *}$ & -0.054 & $-9.20 * * *$ & -0.053 & $-8.86^{* * * *}$ & 1.09 \\
\hline Effort: Accrual Rate & -38.887 & $-2.76 * *$ & & & & & -17.099 & -1.14 & 1.15 \\
\hline Effort: Coupon Frequency & & & -0.307 & $-4.43^{* * * *}$ & & & -0.152 & -1.62 & 1.91 \\
\hline Effort: Coupon Ratio & & & & & -32.563 & $-4.69 * * *$ & -19.402 & $-2.01 * *$ & 1.98 \\
\hline Obs\# & 18644 & & 18687 & & 18687 & & 18644 & & \\
\hline \multicolumn{10}{|l|}{2008} \\
\hline Variable & Beta & $\mathrm{t}$-value & Beta & $\mathrm{t}$-value & Beta & $t$-value & Beta & $t$-value & VIF \\
\hline Intercept & 114.384 & $27.66^{* * *}$ & 114.574 & $27.67^{* * *}$ & 114.817 & $27.74^{* * * *}$ & 114.700 & $27.76^{* * * *}$ & \\
\hline Gender & 2.143 & $1.94^{*}$ & 2.279 & $2.05^{* *}$ & 1.665 & 1.49 & 1.453 & 1.30 & 1.08 \\
\hline Marital Status & 0.472 & 0.36 & 0.532 & 0.41 & 0.967 & 0.74 & 0.883 & 0.68 & 1.22 \\
\hline Online & -17.968 & $-7.21^{* * *}$ & -18.136 & $-7.27^{* * *}$ & -17.483 & $-7.00 * * *$ & -17.668 & $-7.08^{* * * *}$ & 1.07 \\
\hline Tenure & -0.164 & -0.52 & -0.094 & -0.30 & -0.114 & -0.36 & -0.160 & -0.51 & 1.29 \\
\hline Age & 0.690 & $7.18^{* * *}$ & 0.661 & $6.88^{* * * *}$ & 0.674 & $7.01 * * *$ & 0.689 & $7.17^{* * *}$ & 1.40 \\
\hline The Number of Cards Held & -0.197 & $-1.73^{*}$ & -0.245 & $-2.14^{* *}$ & -0.244 & $-2.11^{* *}$ & -0.197 & $-1.73^{*}$ & 1.26 \\
\hline Purchase Amount $(10,000)$ & -0.046 & $-8.82^{* * *}$ & -0.043 & $-8.04^{* * *}$ & -0.046 & $-8.79^{* * * *}$ & -0.045 & $-8.41^{* * * *}$ & 1.14 \\
\hline Effort: Accrual Rate & -44.942 & $-3.31^{1 * * *}$ & & & & & -27.048 & $-1.92 *$ & 1.09 \\
\hline Effort: Coupon Frequency & & & -0.101 & $-3.15^{* * *}$ & & & -0.001 & -0.01 & 1.53 \\
\hline Effort: Coupon Ratio & & & & & -28.242 & $-5.72 * * *$ & -24.044 & $-3.99 * * *$ & 1.54 \\
\hline Obs\# & 18968 & & 19032 & & 19032 & & 18968 & & \\
\hline
\end{tabular}

The positive impact of all three effort level proxy variables on the unit size of redemption point in Table 5 as well as the fact that this positive impact is consistent and very significant both in 2007 and in 2008 except in the case of 'Effort: Coupon frequency' in 2008. This means that the more effort is exerted to accrue points, the larger point size customers tended to redeem. In Table 2 the average of redemption point unit size is 6,000 won (equivalent to US \$ 6). As a customer puts in more effort either by looking for stores providing high point accrual 
〈Table 5〉 Impacts on redemption unit size

\begin{tabular}{|c|c|c|c|c|c|c|c|c|c|}
\hline 2007 & & & & & & & & & \\
\hline Variable & Beta & $t$-value & Beta & $t$-value & Beta & $t$-value & Beta & $t$-value & VIF \\
\hline Intercept & -6087.964 & $-11.55^{* * *}$ & -5637.715 & $-10.72^{* * * *}$ & -5720.312 & $-10.88^{* * * *}$ & -6028.308 & $-11.44^{* * * *}$ & \\
\hline Gender & 541.892 & $3.97^{* * * *}$ & 604.500 & $4.41^{* * * *}$ & 655.671 & $4.77^{* * * *}$ & 628.070 & $4.57^{* * * *}$ & 1.09 \\
\hline Marital Status & 851.840 & $5.38^{* * * *}$ & 809.882 & $5.10^{* * * *}$ & 780.662 & $4.91^{* * * * *}$ & 776.211 & $4.88^{* * * *}$ & 1.22 \\
\hline Online & -2683.631 & $-8.68^{* * *}$ & -2605.371 & $-8.43^{* * *}$ & -2655.084 & $-8.59^{* * *}$ & -2746.387 & $-8.88^{* * * *}$ & 1.06 \\
\hline Tenure & 133.492 & $3.27^{* * * *}$ & 109.287 & $2.68^{* * * *}$ & 112.515 & $2.76^{* * * *}$ & 132.913 & $3.26 * * *$ & 1.26 \\
\hline Age & 331.966 & $27.23^{* * *}$ & 334.389 & $27.51^{* * * *}$ & 332.452 & $27.35^{* * * *}$ & 330.970 & $27.17^{* * * *}$ & 1.40 \\
\hline The Number of Cards Held & 148.670 & $10.80^{* * *}$ & 151.208 & $10.98^{* * * *}$ & 155.071 & $11.28^{* * * *}$ & 147.965 & $10.75^{* * *}$ & 1.23 \\
\hline Purchase Amount $(10,000)$ & 0.002 & $22.12^{* * *}$ & 0.001 & $20.69 * * *$ & 0.002 & $21.69^{* * *}$ & 0.002 & $21.50^{* * *}$ & 1.09 \\
\hline Effort: Accrual Rate & 19508.000 & $11.34^{* * *}$ & & & & & 16064.000 & $8.76^{* * * *}$ & 1.15 \\
\hline Effort: Coupon Frequency & & & 66.380 & $7.86^{* * * *}$ & & & 24.680 & $2.16^{* *}$ & 1.91 \\
\hline Effort: Coupon Ratio & & & & & 7424.144 & $8.78^{* * * *}$ & 2952.027 & $2.50^{* * *}$ & 1.98 \\
\hline Obs \# & 18635 & & 18687 & & 18687 & & 18644 & & \\
\hline \multicolumn{10}{|l|}{2008} \\
\hline Variable & Beta & $\mathrm{t}$-value & Beta & $\mathrm{t}$-value & Beta & $t$-value & Beta & $\mathrm{t}$-value & VIF \\
\hline Intercept & -4947.816 & $-6.81^{* * * *}$ & -4852.106 & $-6.69 * * * *$ & -4884.791 & $-6.73^{* * * *}$ & -4961.430 & $-6.83^{* * * *}$ & \\
\hline Gender & 933.415 & $4.81^{* * * *}$ & 909.432 & $4.68^{* * * *}$ & 1005.534 & $5.14^{* * * *}$ & 988.061 & $5.04 * * *$ & 1.08 \\
\hline Marital Status & 1560.951 & $6.85^{* * * *}$ & 1548.608 & $6.79^{* * * *}$ & 1481.100 & $6.48^{* * * *}$ & 1521.002 & $6.66 * * *$ & 1.22 \\
\hline Online & -2998.987 & $-6.84^{* * * *}$ & -2881.185 & $-6.59^{* * *}$ & -2977.913 & $-6.80^{* * *}$ & -3057.563 & $-6.97^{* * *}$ & 1.07 \\
\hline Tenure & 112.190 & $2.02^{* *}$ & 97.918 & $1.76^{*}$ & 101.234 & $1.82^{*}$ & 112.762 & $2.03^{* *}$ & 1.29 \\
\hline Age & 332.415 & $19.69^{* * *}$ & 340.031 & $20.19^{* * *}$ & 338.782 & $20.12^{* * *}$ & 331.202 & $19.62^{* * *}$ & 1.40 \\
\hline The Number of Cards Held & 116.311 & $5.81^{* * * *}$ & 121.876 & $6.10^{* * * *}$ & 122.183 & $6.12^{* * * *}$ & 116.538 & $5.83^{* * * *}$ & 1.26 \\
\hline Purchase Amount $(10,000)$ & 0.002 & $17.65^{* * *}$ & 0.002 & $16.99^{* * *}$ & 0.002 & $17.28^{* * * *}$ & 0.002 & $17.76^{* * *}$ & 1.14 \\
\hline Effort: Accrual Rate & 14447.000 & $6.05^{* * * *}$ & & & & & 13546.000 & $5.46^{* * * *}$ & 1.09 \\
\hline Effort: Coupon Frequency & & & -0.797 & -0.14 & & & -19.486 & $-2.88^{* * * *}$ & 1.53 \\
\hline Effort: Coupon Ratio & & & & & 3022.536 & $3.49^{* * * *}$ & 3477.191 & $3.28^{* * * *}$ & 1.54 \\
\hline Obs \# & 18968 & & 19032 & & 19032 & & 18968 & & \\
\hline
\end{tabular}

rate or by collecting paper coupons, s/he tends to redeem those points in a larger unit size, for example,10\% accrual rate increase led to the unit size increase of almost $\$ 2$ and 1 collected paper coupon caused an increase of almost 7 cents. As our findings corresponded to our ex- pectation of the positive effect of effort level on redemption unit size, we accept our hypothesis 2 based on findings of Kivetz (2003).

The impact of effort level on hedonic preference of point redemption was consistently negative across effort types as well as different 
$\langle$ Table 6〉 Impacts on redemption hedonic preference

\begin{tabular}{|c|c|c|c|c|c|c|c|c|c|}
\hline 2007 & & & & & & & & & \\
\hline Variable & Beta & $t$-value & Beta & $t$-value & Beta & $t$-value & Beta & $t$-value & VIF \\
\hline Intercept & 1.136 & $70.94 * * *$ & 1.129 & 70.76 **** & 1.131 & $70.90 * * *$ & 1.135 & $70.90^{* * * *}$ & \\
\hline Gender & -0.003 & $-0.81^{* *}$ & -0.004 & $-1.03^{* * *}$ & -0.006 & $-1.42^{* *}$ & -0.006 & -1.32 & 1.09 \\
\hline Marital Status & -0.012 & $-2.47 * * *$ & -0.011 & $-2.32^{* * * *}$ & -0.010 & $-2.07^{* * *}$ & -0.010 & $-2.11 * *$ & 1.22 \\
\hline Online & 0.009 & 0.90 & 0.007 & $0.69^{* * * *}$ & 0.008 & $0.86^{* * * *}$ & 0.010 & 1.08 & 1.06 \\
\hline Tenure & -0.020 & -0.16 & 0.023 & 0.19 & 0.014 & 0.11 & -0.020 & -0.16 & 1.26 \\
\hline Age & -0.879 & $-23.74 * * *$ & -0.884 & $-23.97 * * *$ & -0.879 & $-23.83^{* * *}$ & -0.876 & $-23.65^{* * *}$ & 1.40 \\
\hline The Number of Cards Held & -0.133 & $-3.17^{* * * *}$ & -0.139 & $-3.33^{* * *}$ & -0.144 & $-3.46^{* * *}$ & -0.136 & $-3.24^{* * *}$ & 1.23 \\
\hline Purchase Amount $(10,000)$ & -0.007 & $-3.17 * * *$ & -0.005 & $-2.51^{* * *}$ & -0.006 & $-2.98^{* * *}$ & -0.007 & $-3.16^{* * *}$ & 1.09 \\
\hline Effort: Accrual Rate & -0.323 & -6.18 & & & & & -0.242 & $-4.35^{* * *}$ & 1.15 \\
\hline Effort: Coupon Frequency & & & -0.104 & $-4.07 * * *$ & & & 0.163 & 0.47 & 1.91 \\
\hline Effort: Coupon Ratio & & & & & -0.161 & $-6.29 * * *$ & -0.130 & $-3.63^{* * *}$ & 1.98 \\
\hline Obs \# & 18644 & & 18687 & & 18687 & & 18644 & & \\
\hline \multicolumn{10}{|l|}{2008} \\
\hline Variable & Beta & $t$-value & Beta & $\mathrm{t}$-value & Beta & $t$-value & Beta & $\mathrm{t}$-value & VIF \\
\hline Intercept & 1.039 & $56.33 * * *$ & 1.037 & $56.42 * * *$ & 1.038 & $56.53^{* * * *}$ & 1.039 & $56.38^{* * * *}$ & \\
\hline Gender & -0.044 & $-8.89^{* * * *}$ & -0.044 & $-8.96 * * *$ & -0.047 & $-9.52^{* * *}$ & -0.048 & $-9.61^{* * *}$ & 1.08 \\
\hline Marital Status & -0.045 & $-7.87^{* * * *}$ & -0.045 & $-7.84^{* * *}$ & -0.043 & $-7.46^{* * * *}$ & -0.043 & $-7.35^{* * *}$ & 1.22 \\
\hline Online & -0.009 & $-0.82^{* * * *}$ & -0.010 & $-0.88 * * *$ & -0.007 & $-0.59 * * *$ & -0.005 & -0.49 & 1.07 \\
\hline Tenure & 0.260 & $1.84^{* *}$ & 0.278 & 1.97 & 0.268 & 1.91 & 0.257 & $1.83^{*}$ & 1.29 \\
\hline Age & -0.710 & $-16.58^{* * *}$ & -0.716 & $-16.79 * * *$ & -0.710 & $-16.65^{* * *}$ & -0.708 & $-16.55^{* * *}$ & 1.40 \\
\hline The Number of Cards Held & -0.165 & $-3.24^{* * *}$ & -0.180 & $-3.56 * * *$ & -0.180 & $-3.55^{* * *}$ & -0.171 & $-3.37^{* * *}$ & 1.26 \\
\hline Purchase Amount $(10,000)$ & -0.002 & $-0.92 * * *$ & 0.000 & $0.01 * * *$ & -0.002 & $-0.70^{* * * *}$ & -0.002 & -0.66 & 1.14 \\
\hline Effort: Accrual Rate & -0.214 & $-3.54^{* * * *}$ & & & & & -0.116 & $-1.85^{*}$ & 1.09 \\
\hline Effort: Coupon Frequency & & & -0.056 & $-3.96 * * *$ & & & -0.004 & -0.25 & 1.53 \\
\hline Effort: Coupon Ratio & & & & & -0.145 & $-6.59 * * *$ & -0.131 & $-4.86^{* * *}$ & 1.54 \\
\hline Obs \# & 18968 & & 19032 & & 19032 & & 18968 & & \\
\hline
\end{tabular}

time periods. All three effort variables provided negative impact, which means that customers tended to redeem points for utilitarian products as their effort level increased. Our empirical findings therefore reject the hypothesis 3 based on previous research result explaining that the hedonic preference phenomenon was linked to the dilution of guilty feeling (Kivetz and Simonson 2002). The negative impact of effort level on hedonic redemption would be plausible in case the customers of OK CashBag consider its service as the collection of money. In this case its cus- 
tomers weigh rationally their self-interest which leads to hedonic avoidance compared to the situation where they consider it as simple time investment leading to hedonic preference through product experience focus (Liu and Aaker 2008; Okada and Hoch 2004; Mogilner and Aaker 2009).

\section{Discussion}

\subsection{Empirical Findings}

First, this research explores the impact of accrual behavior, effort level, on three types of redemption behavior: speed, unit size, and hedonic preference of the individual level by using transaction data. Accrual and redemption behaviors are considered the two main components of a loyalty program (Liu 2007). However, the most of previous research focused separately either on the point accrual phase (Hsee et al. 2003: Van Osselaer, Alba, and Manchanda 2004) or on the point redemption phase (Bitner 1995; Gwinner, Gremler, and Bitner 1998; Sheth and Parvatiyar 1995). Through the results of regression analysis, we test the main hypotheses. Hypothesis 1 which states that higher effort level would lead to accelerate redemption speed is accepted. It shows that the effort put in point accrual would accelerate point redemption by increasing temporal discount rate. Hypothesis
2 which states that higher effort level would increase the unit size of redemption amount is accepted. Our findings confirm the result of Kivetz (2003) based on experiment by showing the increased unit size of point redemption which can be generated by the right shift of the value function due to effort put in point accrual. Hypothesis 3 which states that higher effort level would increase the hedonic preference of redemption is rejected. Unlike previous research based on experiments (Kivetz and Simonson 2002) our findings with empirical data show that the negative impact of effort on hedonic preference.

Secondly, this study mobilizes transaction data from a multi-vendor loyalty program in which around 496 affiliate partners participated and whose customers accrued and redeemed reward points very flexibly in terms of product type and point size. Compared to single store based findings (Liu 2007: Smith and Sparks 2009; Taylor and Neslin 2005), which are limited by constraints on point accrual and redemption types and size, and experiment based findings (Hsee 2003; Kivetz 2003; Kivetz 2005; Kivetz and Simonson 2002), our findings can be easily generalized to other loyalty programs in similar conditions. The OK CashBag service allows customers to accrue points through diverse ways, as mentioned in data section, and also offer a variety of products to be gained at various amounts of point redemption. Furthermore, while most existing studies on loyalty programs focus on intent variables such as the customers' will- 
ingness to sign up or their choice of requirements, this study focuses on customers' real behavior using their individual transaction data. Therefore, rather than intent or inclination, variables that reflect real behavior such as how fast points are redeemed, average redeemed point size, and hedonic orientation of redeemed points were measured in order to render a realistic understanding of consumer behavior related to a loyalty program.

Thirdly, we operationalize key variables from accrual and redemption transaction data in order to embrace the fast moving marketing environment that generates substantial volume of transaction data. Compared to research using survey or experiment data, empirical research using operationalized variables have advantages such as enhanced validity of analysis result by double checking the analysis results of different time periods and generalizability of measurement methods of variables to similar loyalty programs in different markets. Effort level is operationalized as fixed frequency or amount of point accrual by Kivetz and Simonson (2002), however in this study not only frequency but also different amounts of effort exertion according to method is accounted for, thus allowing for a more in-depth and true to life depiction of effort level. For redemption behavior we adopted the FIFO method to calculate the speed of point redemption by measuring the elapsed time of point possession between accrual and redemption time.

\subsection{Managerial Implications}

First of all, our approach of operationalizing proxy variables from transaction data sheds light for companies running a similar loyalty program by allowing them to elaborate major characteristics related to point accrual and redemption behavior of customers without using surveys. The variables mobilized in our study were measured objectively and are easily replicable and can be updated regularly using the latest transaction data. Most importantly, our approach can be applied to all customers allowing the execution of individual level target marketing activities.

Secondly as our study is based on empirical data from OK CashBag, a comprehensive multivendor loyalty program, our findings are more generally applicable compared to single store based studies (Liu 2007; Smith and Sparks 2009; Taylor and Neslin 2005) and multi-vendor but survey based studies (Dorotic et al. 2011; Meyer-waarden and Benavent 2006). Our findings can be easily applied to companies running a loyalty program under special environments in terms of the number of service providers and reward redemption variety and flexibility. Customers of OK Cashbag can purchase and accrue points from diverse affiliate partners such as on and off-line retailers, service providers and consumer package manufacturers by using diverse membership related payment methods from multiple financial service companies. Furthermore, customers can redeem reward points 
very flexibly in terms of store type and point unit size.

Finally, understanding customer dynamics of reward accrual and redemption behavior at the individual level is one of the keys for successful management of a customized loyalty program (Smith and Sparks 2009; Dorotic, Bijmolt and Verhoef 2012). The three redemption behavior related variables of speed, unit size and hedonic preference explain very different aspects of redemption behavior with substantial heterogeneity among customers. The three proxy variables of effort level (accrual rate, paper coupon frequency and ratio) also highlight the heterogeneity of customers' degree to put effort in accruing reward points through diverse methods. By proposing a method to operationalize proxy variables of customer characteristics, our findings help marketing practitioners involved in a loyalty program to manage their customers' effort level and its influence on redemption behavior which can reinforce the virtuous cycle of reward point accrual and redemption behavior ( Liu 2007).

\subsection{Limitations and Future Research}

We develop our hypothesis 1 by extending the findings of previous research on sunk cost effect (Thaler 1980) and test it by using empirical data from a single data source. However, no previous research was conducted to test directly the impact of effort level on temporal discount rate. Therefore, it is recommended to conduct a series of experiments to confirm our findings as well as to empirically replicate our findings with similar loyalty program transaction data under different market situations. As for hypothesis 3 , we find the above analysis results by assessing the difference between randomly chosen individuals and assuming a causal relationship between accrual effort level and redemption behavior in time. Even though the two types of behavior are chronologically ordered, the causal relationship we tested could be inversed due to intrinsic characteristics of consumers. For example, consumers having high utilitarian preference may expend high effort before redeeming utilitarian rewards. It means that in some cases it would not be realistic to expect the same results of experiment based studies (with randomized subjects) in empirical ones because of sampling issues related to the phenomenon of intrinsic characteristics. Therefore, it is recommended to conduct additional research to check our findings in different contexts in order to address the issue of the plausible conflict of analysis results between experiment and empirical research.

In this study, we operationalize three proxy variables from transaction data to measure the effort level without survey. Therefore, our approach is embedded with a certain degree of vulnerability on the following issues: 1) whether it is certain that what we measured is the "effort level' of reward accrual behavior (validity) and 2) 
whether all three proxy variables correctly measure the same construct (reliability). To enhance the validity of the research, it would be possible to conduct a survey with questions designed to measure the perceived level of effort of customers or to develop another set of proxy variables from the different types of behavior of the same person, such as promotion response, then cross checking the relationship between proxy variables representing the same construct. Nevertheless, the consistent impact of three chosen effort variables on redemption behavior in our study alleviates concerns about this issue.

Our data set contains all reward accrual (purchase with the loyalty card) and redemption transactions with their time. So it would be possible to develop a dynamic model to predict future behavior such as redemption timing depending on effort level. However, in this study, we aggregate transaction data during a given period (i.e., year) and test the impact of effort level on redemption behavior measured on average. Our analyses are limited to explaining the dynamics between transactions and do not incorporate individual heterogeneity into the model. Instead their effects in the regression analysis were controlled. By using a dynamic model with immediate utility maximization, as proposed by Erdem and Keane (1996), as well as the dynamic forward looking model, our study could lead to the realization of a model proposing optimal accrual methods to accelerate redemption speed, increase redemption unit size, and lead hedonic items for redemption.

〈Received February 11. 2017〉

〈Revised February 11. 2017〉

〈Accepted February 12. 2017〉

\section{References}

Anderson, Ronald D., Jack L. Engledow and Helmut Becker (1979), "Evaluating the Relationships among Attitude Toward Business, Product Satisfaction, Experience, and Search Effort," Journal of Marketing Research, 16 (3), 394-400.

Batra, Rajeev and Olli T. Ahtola (1991), "Measuring the Hedonic and Utilitarian Sources of Consumer Attitudes," Marketing Letters, 2 (2), 159-70.

Bell, Simon J., Seigyoung Auh and Karen Smalley (2005), “Customer Relationship Dynamics: Service Quality and Customer Loyalty in the Context of Varying Levels of Customer Expertise and Switching costs," Journal of the Academy of Marketing Science, 33 (2), 169-83.

Berry, Christopher J. (1994), The Idea of Luxury. Cambridge, UK: Cambridge University Press. Bitner, Mary Jo (1995), "Building Service Relationships: It's All about Promises," Journal of the Academy of Marketing Science, 23 (4), 246-51.

Blattberg, Robert C., Byung-Do Kim and Scott 
A. Neslin (2008). Database Marketing: Analyzing and Managing Customers. New York: Springer.

Bolton, Ruth. N. (1998), “A Dynamic Model of the Duration of the Customer's Relationship with a Continuous Service Provider: The Role of Satisfaction," Marketing science, 17 (1), 45-65.

Caplin, Andrew and John Leahy (2001), "Psychological Expected Utility Theory and Anticipatory Feelings," Quarterly Journal of Economics, 116 (1), 55-79.

Cardozo, Richard N. (1965), "An Experimental Study of Customer Effort, Expectation, and Satisfaction," Journal of Marketing Research, 2 (3), 244-49.

Chang, Myron N. and Grace L. Yang (1987), "Strong Consistency of a Nonparametric Estimator of the survival Function with Doubly Censored data," The Annals of Statistics, 15 (4), 1536-47.

Daughtrey, Clayton L., Nicole S. Vowles and Gregory S. Black (2013), “The Effects of Membership and Demographics on Consumer Satisfaction and Loyalty in Service Organizations," Services Marketing Quarterly, 34 (4), 292-308.

Dellaert, Benedict G. C. and Barbara E. Kahn (1999), "How Tolerable Is Delay? Consumers' Evaluations of Internet Web Sites after Waiting," Journal of Interactive Marketing, 13 (1), 41-54

Dorotic, Matilda, Dennis Fok, Peter C. Verhoef and Tammo H. A. Bijmolt (2011), "Do Vendors Benefit from Promotions in a MultiVendor Loyalty Program?," Marketing Letters, 22 (4), 341-56.

Dorotic, Matilda, Tammo H. A. Bijmolt and Peter C. Verhoef (2012), "Loyalty Programmes: Current Knowledge and Research Directions," International Journal of Management Reviews, 14 (3), 217-37.

Drèze, Xavier and Joseph C. Nunes (2011), "Recurring Goals and Learning: The Impact of Successful Reward Attainment on Purchase Behavior," Journal of Marketing Research, 48 (1), 268-81.

Erdem, Tülin and Michael P. Keane (1996), "Decision-Making under Uncertainty: Capturing Dynamic Brand Choice Processes in Turbulent Consumer Goods Markets," Marketing Science,15 (1), 1-20.

Gomez, B. G., A. G. Arranz and J. G. Cillan (2006), "The Role of Loyalty Programs in Behavioural and Affective Loyalty," Journal of Consumer Marketing, 23 (7), 387-96.

Gourville, John T. and Dilip Soman (1998), "Payment Depreciation: The Behavioral Effects of Temporally Separating Payments from Consumption," Journal of Consumer Research, 25 (2), 160-74.

Gwinner, Kevin P., Dwayne D. Gremler, and Mary Jo Bitner (1998), "Relational Benefits in Services Industries: The Customer's Perspective," Journal of the Academy of Marketing Science, 26 (2), 101-14. 
Hirschman, Elizabeth C. and Morris B. Holbrook (1982), "Hedonic Consumption: Emerging Concepts, Methods and Propositions," Journal of Marketing, 46 (3), 92-101.

Hsee, Christopher K., Fang Yu, Jiao Zhang and Yan Zhang (2003), "Medium Maximization," Journal of Consumer Research, 30 (1), 1-14. Humby, Clive, Terry Hunt and Tim Phillips (2003), Scoring Points: How Tesco is Winning Customer Loyalty, London: Kogan Page.

Jones, Michael A., David L Mothersbaugh and Sharon E Beatty (2000), "Switching Barriers and Repurchase Intentions in Services," Journal of Retailing, 76 (2), 259-74.

Kahneman, Daniel and Amos Tversky (1979), "Prospect Theory: An Analysis of Decision Under Risk," Econometrica, 47 (4), 263-91. Kivetz, Ran (1999), "Advances in Research on Mental Accounting and Reason-Based Choice," Marketing Letters, 10 (3), 249-66. Kivetz, Ran (2003), "The Effects of Effort and Intrinsic Motivation on Risky Choice," Marketing Science, 22 (4), 477-502.

Kivetz, Ran (2005), "Promotion Reactance: The Role of Effort-Reward Congruity," Journal of Consumer Research, 31 (4), 725-36.

Kivetz, Ran and Itamar Simonson (2002), "Earning the Right to Indulge: Effort as a Determinant of Customer Preference toward Frequency Program Rewards," Journal of Marketing Research, 34 (2), 155-70.

Kivetz, Ran and ltamar Simonson (2003), "The
Idiosyncratic Fit Heuristic: Effort Advantages as a Determinant of Consumer Response to Loyalty Programs," Journal of Marketing Research, 40 (4), 454-67.

Kivetz, Ran, Oleg Urmisky and Yuhuang Zheng (2006), "The Goal-Gradient Hypothesis Resurrected: Purchase Acceleration, Illusionary Goal Progress, and Customer Retention," Journal of Marketing Research, 43 (1), 39-58.

Lascu, Dana N. (1991), "Consumer Guilt: Examining the Potential of a New Marketing Construct," Advances in Consumer Research, Vol. 18, Rebecca Holman and Michael Solomon, eds. Provo, UT: Association for Consumer Research, 290-93.

Liu, Yuping (2007), “The Long-Term Impact of Loyalty Programs on Consumer Purchase Behavior and Loyalty," Journal of Marketing, 71 (4), 19-35.

Liu, Wendy and Jennifer Aaker (2008), "The Happiness of Giving: The Time-Ask Effect," Journal of Consumer Research, 35 (3), 54357.

Loewenstein, George (1987), “Anticipation and the Valuation of Delayed Consumption," Economic Journal, 97 (387), 666-84.

Loewenstein, George and Drazen Prelec (1992), "Anomalies in Intertemporal Choice: Evidence and an Interpretation," Quarterly Journal of Economics, 107 (2), 573-97.

Meyer-Waarden, Lars. (2007), "The Effects of Loyalty Programs on Customer Lifetime 
Duration and Share of Wallet," Journal of Retailing, 83 (2), 223-36.

Meyer-Waarden, Lars. and Christophe Benavent (2006), "The Impact of Loyalty Programs on Repeat Purchase Behaviour," Journal of Marketing Management, 22 (1-2), 61-88.

Mischel, Walter, Joan Grusec and John C. Masters (1969), "Effects of Expected Delay Time on the Subjective Value of Rewards and Punishments," Journal of Personality and Social Psychology, 11 (4), 363-73.

Mittal, Banwari (1989), “A Theoretical Analysis of Two Recent Measures of Involvement," in NA - Advances in Consumer Research Volume 16, eds. Thomas K. Srull, Provo, UT : Association for Consumer Research, 697-702.

Mogilner Cassie and Aaker, Jennifer (2009), "The Time vs. Money Effect: Shifting Product Attitudes and Decisions through Personal Connection," Journal of Consumer Research, 36 (2), 277-91.

Ngobo, Paul-Valentin and Delphine DevalletEzanno (2010), "Do Generations Matter in Customer Defection?," Recherche et Applications en Marketing [English ed.], 25 (3), 85-112.

Nisan, Mordecai (1973), "Evaluation of Temporally Distant Reinforcements," Journal of Personality and Social Psychology, 26(2), 295300.

Nunes, Joseph C. and Xavier Drèze (2006), "Your loyalty Program is Betraying You,"
Harvard Business Review, 84 (4), 124-31. Ogden, James R. and Ogden, Denis T. (2005), Retailing: Integrated Retail Management, chapter 8. Houghton Mifflin.

Okada, Erica Mina and Stephen J. Hoch (2004), "Spending Time Versus Spending Money," Journal of Consumer Research, 31 (2), 313-23.

Patterson, Paul G. (2007), "Demographic Correlates of Loyalty in a Service Context," Journal of Services Marketing, 21 (2), 11221.

Prelec, Drazen and Richard J. Herrnstein (1991), "References or Principles: Alternative Guidelines for Choice," in Strategy and Choice, Richard J. Zeckhauser, eds. Cambridge, MA: MIT Press, 319-40.

Reinartz, Werner, Jacquelyn S. Thomas, and V. Kumar (2005), "Balancing Acquisition and Retention Resources to Maximize Customer Profitability," Journal of Marketing, 69 (1), 63-79.

Sheth, Jagdish N. and Atul Parvatiyar (1995), "Relationship Marketing in Consumer Markets: Antecedents and Consequences," Journal of the Academy of Marketing Science, 23 (4), 255-71.

Smith, Andrew and Leigh Sparks (2009), "Reward Redemption Behaviour in Retail Loyalty Schemes," British Journal of Management, 20 (2), 204-18.

Soman, Dilip (1998), "The Illusion of Delayed Incentives: Evaluating Future Effort - 
Money Transactions," Journal of Marketing Research, 35 (3), 427-37.

Strahilevitz, Michal A. and John G. Myers (1998), "Donations to Charity as Purchase Incentives: How Well They Work May Depend on What You Are Trying to Sell," Journal of Consumer Research, 24 (4), 43446.

Taylor, Gail Ayala and Scott A. Neslin (2005), "The Current and Future Sales Impact of a Retail Frequency Reward Program," Journal of Retailing, 81 (4), 293-305.
Thaler, Richard(1980), "Toward a Positive theory of Consumer Choice," Journal of Economic Behavior \& Organization, 1(1), 39-60.

Thomas, Jacquelyn S.(2001), "A Methodology for Linking Customer Acquisition to Customer Retention," Journal of Marketing Research, 38(2), 262-268.

Vaughn, Richard(1980), "How Advertising Works: A Planning Model," Journal of Advertising Research.

Zaichkowsky, Judith Lynne(1985), "Measuring the Involvement Construct," Journal of Consumer Research, 12(3), 341-352. 


\section{〈Appendix〉 Variable Computation}

Appendix table 1 provides an extrapolation of transaction data of one customer labeled as 'A01'. This customer made nine transactions (seven for accrual and two for redemption) between January 1 and April 5 in 2007. The variable 'Effort: Accrual rate' represents the average accrual rate of seven point accruals. In this example, 'Effort: Accrual rate' of A01 is $(1 \%+1 \%+0.5 \%+1 \%+0.5 \%+1 \%) / 6=0.83 \%$. The variable 'Effort: Coupon frequency' was counting the frequency of coupon accrual transactions, 1 . The Variable 'Effort: Coupon proportion' was measured as the proportion of point accrual frequency of paper coupon over frequency of all point accrual transaction. In this case, it became 1/7.

Redemption speed was calculated based on FIFO method. 1,000 points redeemed on February 25 were accrued as100 points on January 1 (55 elapsed days), 300 points on January 15 (40 elapsed days), 500 points on February 2 (23 elapsed days), and 100 points on February 15 (10 elapsed days). So we computed the weighted average of elapsed time (in day) for 1,000 redeemed point on February 25 as following: $55 * 100 / 1000+40 * 300 / 1000+23 * 500 / 1000+10 * 100 / 1000=30$ days. On average 1,000 points redeemed on February 25 stayed for 30 days under the possession of customer 'A01'. In the same manner the 'Redemption speed' of 500 points redeemed on April 5 was calculated as $49 * 200 / 500+34 * 300 / 500=40$ days. Therefore, the average redemption speed of 'A01' became 33.3 days. Left censoring was necessary to handle the data as we did not have the full information of point accrual and redemption data from the start date of service for each customer. A censoring method used by companies in case of data loss or system malfunction (Chang and Yang 1987) was applied to calculate redemption speed. When redeemed points surpassed the sum of points accrued, the start date of analysis (in our case Jan 1 of each year) was applied to the accrual data of unmatched points. When we compared 'redemption speed' with a data set with full previous accrual and redemption information, left-censored redemption speed showed a correlation of 0.96 with the full information redemption speed and its mean absolute deviation was 7. Therefore, we applied this left censoring method for our data set.

〈Appendix table 1〉 Transaction data example

\begin{tabular}{ccccccccc}
\hline ID & Transaction Type & Date & Outlet & $\begin{array}{c}\text { Sales } \\
\text { Amount }\end{array}$ & $\begin{array}{c}\text { Hedonic } \\
\text { Index }\end{array}$ & $\begin{array}{c}\text { Points } \\
\text { Accrued }\end{array}$ & $\begin{array}{c}\text { Points } \\
\text { Redeemed }\end{array}$ & $\begin{array}{c}\text { Accrual } \\
\text { Rate }\end{array}$ \\
\hline A01 & Accrual: regular & $2007 / 01 / 01$ & O11575 & 10,000 & 0 & 100 & - & $1.0 \%$ \\
& Accrual: regular & $2007 / 01 / 15$ & O11478 & 30,000 & 1 & 300 & - & $1.0 \%$ \\
& Accrual: coupon & $2007 / 02 / 02$ & K10505 & & 1 & 500 & - & \\
& Accrual: regular & $2007 / 02 / 15$ & I50001 & 60,000 & 0 & 300 & - & $0.5 \%$ \\
& Redemption & $2007 / 02 / 25$ & O20001 & 1,000 & 0 & - & 1,000 & \\
Accrual: bill & $2007 / 03 / 01$ & I60001 & 50,000 & 0 & 500 & - & $1.0 \%$ \\
Accrual: regular & $2007 / 03 / 15$ & I50001 & 50,000 & 0 & 250 & - & $0.5 \%$ \\
Accrual: bill & $2007 / 04 / 01$ & O2001 & 70,000 & 0 & 700 & - & $1.0 \%$ \\
Redemption & $2007 / 04 / 05$ & A00001 & 500 & 1 & - & 500 & \\
\hline
\end{tabular}

